\title{
Spore Release of Bremia lactucae on Lettuce Is Affected by Timing of Light Initiation and Decrease in Relative Humidity
}

\author{
H. Su, A. H. C. van Bruggen, and K. V. Subbarao
}

First and second authors: Department of Plant Pathology, University of California, Davis 95616; third author: Department of Plant Pathology, University of California, Davis, c/o U.S. Agricultural Research Station, 1636 E. Alisal St., Salinas 93905.

Accepted for publication 21 September 1999.

\begin{abstract}
Su, H., van Bruggen, A. H. C., and Subbarao, K. V. 2000. Spore release of Bremia lactucae on lettuce is affected by timing of light initiation and decrease in relative humidity. Phytopathology 90:67-71.

A suction-impaction mini-spore trap was developed to study the effect of light initiation and decreasing relative humidity $(\mathrm{RH})$ on spore release of Bremia lactucae in a controlled environment. Three light periods (from 0400 to 1600,0600 to 1800 , and 0800 to $2000 \mathrm{~h}$, circadian time) at a constant RH of 99 to $100 \%$ were used for studying the effect of light initiation on spore release. Few spores were released during the dark periods. Spore release increased sharply after the initiation of the three

declined until only a few spores could be detected. The effect of reduction in $\mathrm{RH}$ on spore release was studied by comparing decreases in $\mathrm{RH}$ $2 \mathrm{~h}$ before and $2 \mathrm{~h}$ after light initiation at $0800 \mathrm{~h}$. When RH decreased from 100 to $94 \% 2 \mathrm{~h}$ before light initiation, spore release increased within $1 \mathrm{~h}$, followed by a second increase after light initiation. When RH decreased $2 \mathrm{~h}$ after light initiation, spore release continued to increase after the initial increase after light initiation, reached a maximum $1 \mathrm{~h}$ after the reduction in $\mathrm{RH}$, and then declined. The results suggest that both light initiation and reduction in $\mathrm{RH}$ can trigger spore release and that these factors have separate effects on spore release of Bremia lactucae.
\end{abstract} light periods, reached a maximum 1 to $2 \mathrm{~h}$ after light initiation, and then

Spore release is an important process in disease epidemics. Spore release studies lead to a better understanding of spore dissemination and in turn to new insights into the mechanisms underlying disease spread. Many environmental or endogenous factors, such as relative humidity $(\mathrm{RH})$, water film on leaves, wind, rain, or periodicity in the fungi, may be involved in the process of spore release (18). For many airborne pathogens, RH and light are two important factors affecting spore discharge (12). Spore release of Peronospora tabacina was related to hygroscopic movement of sporangiophores due to humidity changes in the surrounding environment. Other members of the Peronosporales were considered to have a similar spore liberation mechanism (20). Leach (11-15) demonstrated that spores of Drechslera turcica were discharged when the electric field of the leaf changed and suggested an electrostatic theory for spore release. Leaf surface potentials could be affected by RH, moving air, red-infrared radiation, and, more importantly, light regime, which initiates spore liberation. Leach $(17,18)$ also showed that a similar mechanism underlies spore release of $P$. destructor. Some endogenous factors also may control the process of spore release. According to Bell-Pedersen et al. (1), the circadian clock of a fungus controls the rhythm of spore development, and release and light is the main factor regulating the circadian rhythm, a periodicity that is close to $24 \mathrm{~h}$ (26). However, effects of circadian rhythm on spore release would be difficult to separate from those of environmental factors under field conditions.

Both RH and light may play an important role in spore release of Bremia lactucae Regel. Fletcher (4) showed that spore release of $B$. lactucae corresponded to decreases in environmental $\mathrm{RH}$. Scherm and van Bruggen (24) hypothesized that spore release of $B$. lactucae was initiated at sunrise because infection occurred

Corresponding author: H. Su; E-mail address: hsu@ucdavis.edu

Publication no. P-1999-1108-01R

(C) 2000 The American Phytopathological Society
Additional keywords: spore trap, sporulation. within a 3-h leaf wetness period after sunrise when test plants were only exposed to inoculum during the night and next morning. Spore release, as measured by a Burkard trap, often occurred before a reduction in $\mathrm{RH}$ in the morning (24). However, the relative importance of light and decrease in $\mathrm{RH}$ for spore release of $B$. lactucae has not been studied. In this study, we determined the effect of timing of light initiation and RH reduction on spore release of B. lactucae.

The choice of a proper spore-trapping instrument to obtain an accurate estimation of spore liberation is an important consideration. Because of the importance of spore release in disease epidemics and the complex factors involved in the process of spore release, many methods and instruments have been developed for trapping spores $(2,3,5,6,8-10,13,19,23)$. Despite a plethora of devices developed for different purposes, adoption of one for this study was difficult because some require large space or complex parts, and others were designed for field studies. We designed a small spore trap to study the effect of light initiation in combination with $\mathrm{RH}$ on spore release of $B$. lactucae.

\section{MATERIALS AND METHODS}

Development of the spore-trapping system. A clock from a common hygrothermograph (Bendix Aviation Co., Baltimore) was set for a revolution of $24 \mathrm{~h}$ and was attached to the bottom of a crisper box $(31.1 \times 22.9 \times 10.5 \mathrm{~cm}$; Tri State Molded Plastics, Dixon, KY). The crisper box with the attached clock faced down without a lid, and was connected to another crisper box facing up without a lid, to form an enclosed trap chamber (Fig. 1). A third crisper box was attached with glue facing up on top of the trap chamber to form an air-circulation chamber. The chamber was sealed with 19-mm-wide transparent tape. A vertical plastic tunnel with an orifice at the bottom $(65 \times 65 \mathrm{~mm}$ square and $70 \mathrm{~mm}$ long $)$ connected to the air-circulation chamber and trap chambers. A $55-\mathrm{mm}$ fan (12 DV, $1.0 \mathrm{~W}$ ) was fixed at $30 \mathrm{~mm}$ from the upper end, inside the tunnel, to generate an upward air flow to intake the 
spores from trap chamber through the orifice into the tunnel along with the air. The rate of airflow passing through the orifice was 1.3 liters/min. The circulated air from the upper chamber returned to the trap chamber through a connection tube. A drum $(57 \mathrm{~mm}$ wide) inside the tunnel was connected to the clock with a plastic axle. A small piece of double-sided adhesive tape was attached to the starting line on the drum to hold both ends of a single-sided adhesive tape $(8 \times 368 \mathrm{~mm})$, wrapped around the drum with the exposed adhesive side to trap spores, for a 24-h cycle. Petroleum jelly or glycerol was not applied to prevent the spores from dehydration as recommended $(10,19)$, because the tape could be preserved by just laying it on a slide, and all the trapped spores belonged to B. lactucae. Spores were trapped continuously when the adhesive surface of the drum passed by the orifice $(1 \times 10 \mathrm{~mm})$ at $1 \mathrm{~mm}$ from the orifice at the bottom of the tunnel.

The bottom of the trap chamber was partially removed. The trap chamber was placed in a RH chamber formed by a crisper box containing double-distilled water or a saturated ammonium sulfate solution $\left(\left(\mathrm{NH}_{4}\right)_{2} \mathrm{SO}_{4}\right)(21)$. Higher $\mathrm{RH}(100 \%)$ was maintained with double-distilled water and lower RH was maintained with saturated ammonium sulfate in two separate crisper boxes. Changes in $\mathrm{RH}$ were obtained by switching the $\mathrm{RH}$ chambers. $\mathrm{RH}$ fluctuated from 100 to 94 to $96 \%$ in about an hour after the switch from double-distilled water to saturated ammonium sulfate solution (Fig. $2 \mathrm{~A}$ and B). Lower RH levels were not attained, although we expected the lowest RH that could be achieved with saturated ammonium sulfate would be $81 \%$. A model 207 temperature and $\mathrm{RH}$ probe (Campbell Scientific, Inc., Logan, UT) connected to a data logger was placed beside the sample plants to measure RH. After the plants were placed in the trap chamber or after the RH chamber was switched, the connections were sealed with transparent tape. The spore-trapping system was placed in a growth chamber $70 \mathrm{~cm}$ away from 15 fluorescent light tubes (160 W, Philips Lighting Company, Somerset, NJ). The light intensity reaching the plants inside the trap chamber was $74 \mathrm{~W} \mathrm{~s}^{-1} \mathrm{~m}^{-2}$ as measured by the Quantum sensor (Campbell Scientific).

Isolate, plants, and inoculation. Isolate $\mathrm{C} 97 \mathrm{H} 578$ of $\mathrm{B}$. lactu$c a e$, identified as pathotype $\mathrm{V}$, was used for inoculation. This isolate was collected from the Salinas Valley in a survey during August
1997 and propagated on cv. Cobham Green. Seeds of Cobham Green were planted in pots $(5 \times 5 \times 6.25 \mathrm{~cm})$. The potting soil used was a UC mix consisting of $40 \%$ washed sand, $20 \%$ nitrified redwood compost, $20 \%$ sphagnum peat moss, and $20 \%$ pumice rock. The pots were kept at $15^{\circ} \mathrm{C}$, under a 12 -h light period at $100 \% \mathrm{RH}$ in crisper boxes in a growth chamber. After 10 days, when the cotyledons had unfolded, but before true leaves emerged, they were used for inoculation. Plants were watered from the bottom of the pots and maintained in the growth chamber until inoculation. Inoculum was prepared by washing the sporulating cotyledons of $\mathrm{cv}$. Cobham Green with $20 \mathrm{ml}$ of double-distilled water after incubation for 6 days. The spore concentration was adjusted to $10^{4}$ to $10^{5}$ sporangia per $\mathrm{ml}$, and sporangia were sprayed with a compressed air sprayer to runoff on plants.

Incubation, light period, and RH treatments. Inoculated cotyledons were incubated in the dark at $15^{\circ} \mathrm{C}$ and $100 \% \mathrm{RH}$ in crisper boxes in a growth chamber for $24 \mathrm{~h}$ to ensure infection. Cotyledons were exposed to a 12-h light regime beginning at $0400 \mathrm{~h}$, circadian time. After the plants had been sporulating for 3 days, they were transferred to the spore-trap chamber located in the same growth chamber. Preliminary experiments revealed that infected

TABLE 1. Results of repeated-measures analysis of variance of the percentage of spores trapped per hour during 24 -h periods at $100 \%$ relative humidity $(\mathrm{RH})$ and per hour during 24-h periods in RH-reduction treatments

\begin{tabular}{lllrrr}
\hline Experiment & \multicolumn{1}{c}{ Source $^{\mathrm{v}}$} & $\mathrm{df}^{\mathrm{w}}$ & $\mathrm{MS}^{\mathrm{x}}$ & \multicolumn{1}{c}{$F$} & $P>F^{\mathrm{y}}$ \\
\hline Light timing & Time & 23 & 264.1 & 11.98 & 0.0001 \\
& Time $\times$ treat. & 46 & 203.1 & 9.21 & 0.0001 \\
& Time $\times$ rep. & 46 & 14.4 & 0.65 & 0.8551 \\
$\mathrm{RH}^{\mathrm{z}}$ & & & & & \\
& Time & 23 & 127.7 & 17.06 & 0.0001 \\
& Time $\times$ treat. & 23 & 30.3 & 4.05 & 0.0001 \\
& Time $\times$ rep. & 46 & 11.3 & 1.50 & 0.0858 \\
\hline
\end{tabular}

${ }^{\mathrm{v}}$ Time $=24$-h period; treat. $=$ three light-timing treatments: 0400 to 1600,0600 to 1800 , and 0800 to $2000 \mathrm{~h}$, circadian time; and rep. = repetition.

${ }^{w}$ Degrees of freedom.

${ }^{x}$ Mean square.

y Probability associated with $F$ test.

${ }^{\mathrm{z}} \mathrm{RH}-$ reduction treatments of $2 \mathrm{~h}$ before and after light initiation at $0800 \mathrm{~h}$.

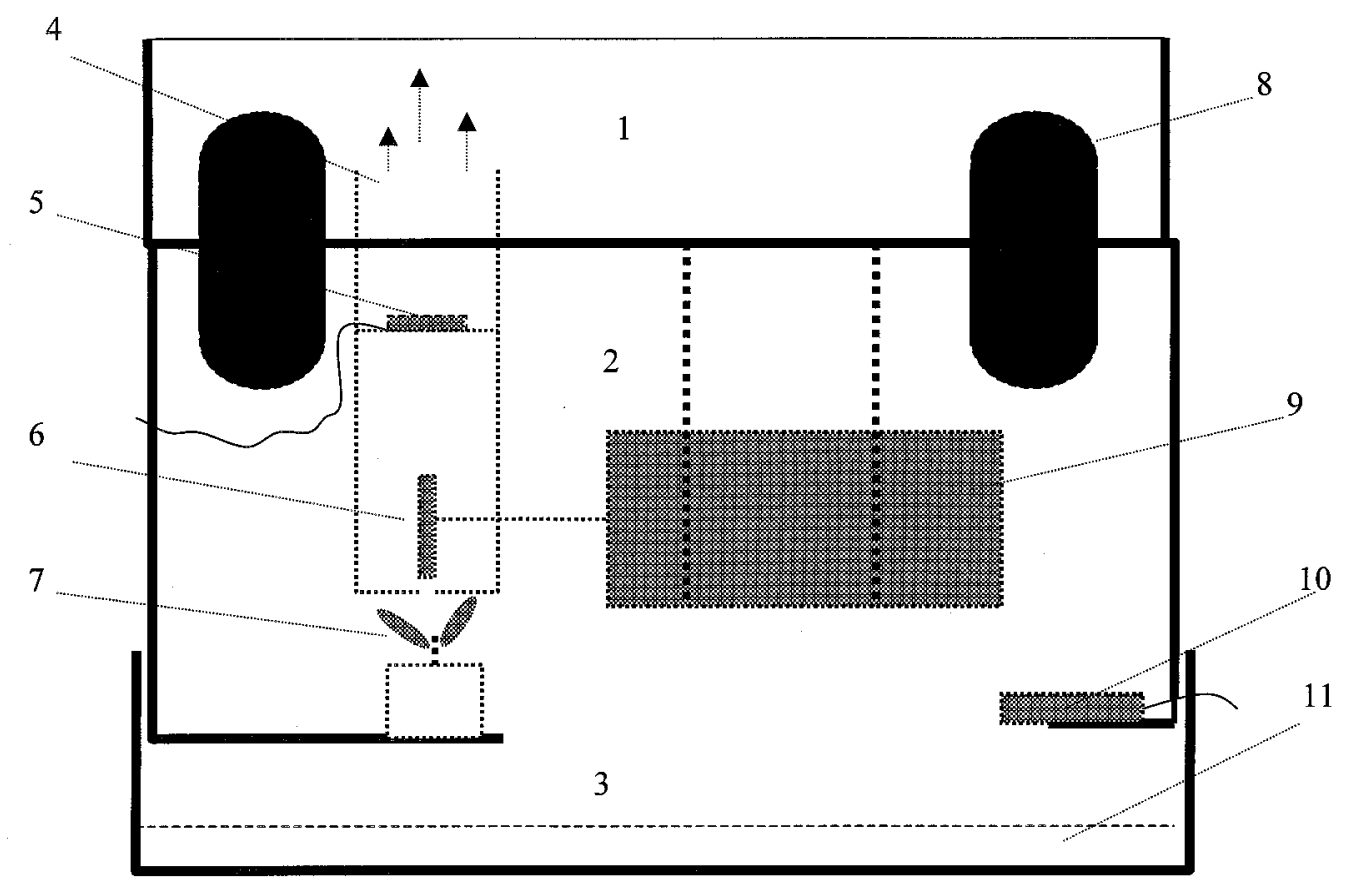

Fig. 1. Diagram of spore trap: 1, air-circulation chamber; 2, trap chamber; 3, relative humidity (RH) chamber; 4, tunnel; 5, fan with wire; 6, drum with tape; 7, plants; 8 , connection tubing between air-circulation and trap chambers; 9 , hygrothermometer clock; $10, \mathrm{RH}$ sensor with wire; 11, double-distilled water or saturated ammonium sulfate solution. 
plants release almost no spores at $\approx 2200 \mathrm{~h}$. Therefore, for each experiment and treatment, a pot with infected plants was transferred to the trap chamber and clean sticky tape was wrapped on the drum at $2200 \mathrm{~h}$. Sporangia were trapped continuously for $24 \mathrm{~h}$. Three light periods, from 0400 to 1600,0600 to 1800 , and 0800 to $2000 \mathrm{~h}$, were used for spore-release studies. Each light-initiation treatment was repeated three times in three 24 -h periods. Three different pots (each with 50 seedlings) were used for three repetitions of each light-initiation treatment.

Counting sporangia. After trapping the spores for $24 \mathrm{~h}$, the adhesive tape was detached from the drum and divided into four pieces, each $46 \mathrm{~mm}$ long. Each piece of tape was placed face up on a microscope slide and marked at intervals of $7.67 \mathrm{~mm}$, which is the distance the drum moves each hour. The number of spores released per hour in the 24 -h period was counted under a microscope.

Statistical analysis. Because the total number of spores trapped in 24-h periods varied between replications of each light-initiation treatment and between different light-initiation treatments, the percentage of spores released per hour in relation to the total number of spores trapped in a 24-h period was calculated. The percentages of spores trapped were subjected to repeated measures analysis of variance with light-initiation treatments or RH-reduction treatments as independent variables and numbers of hours in 24-h periods as
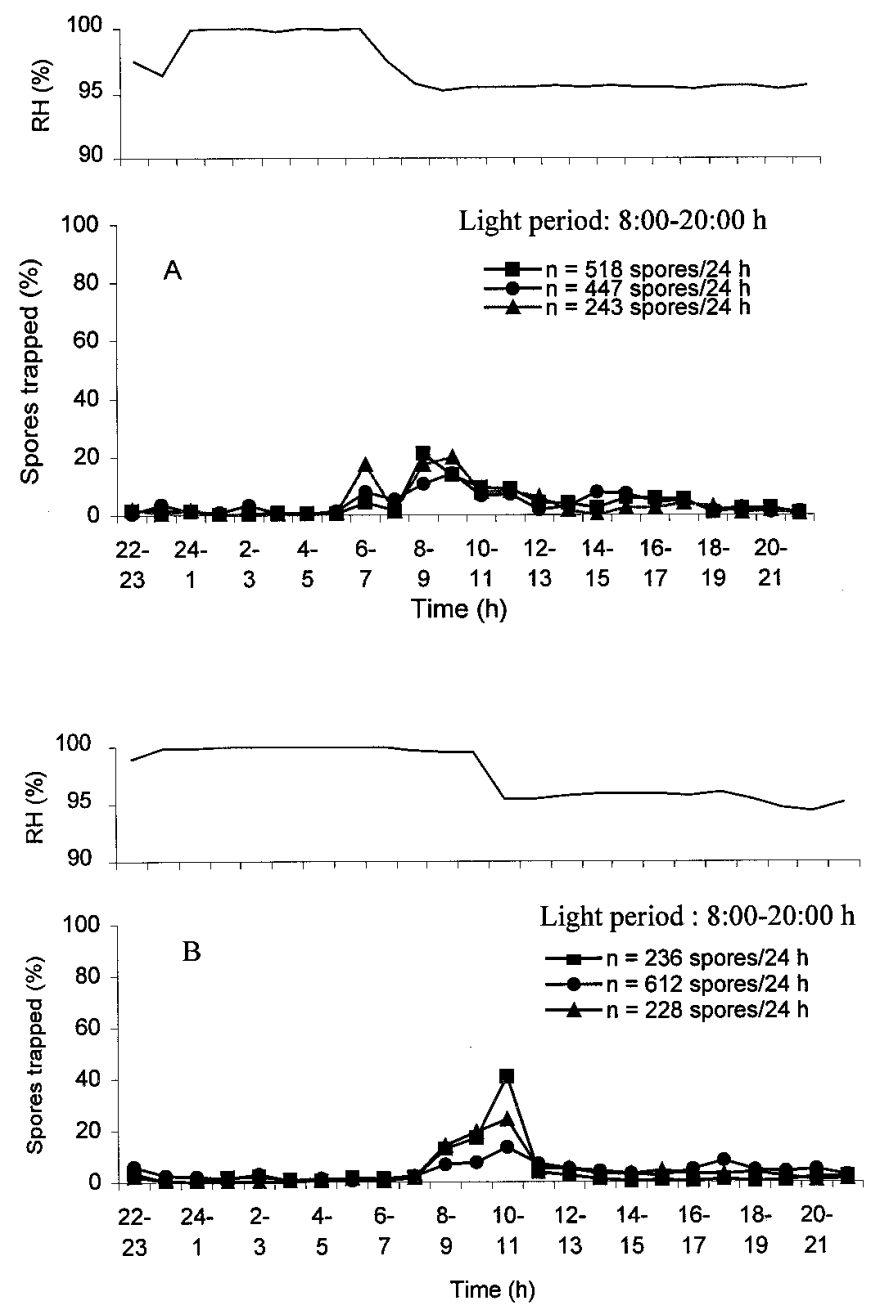

Fig. 2. Percentage of spores trapped when relative humidity (RH) changed $\mathbf{A}$, $2 \mathrm{~h}$ before and $\mathbf{B}, 2 \mathrm{~h}$ after light initiation $(0800 \mathrm{~h}$, circadian time) during three 24-h periods ( $\boldsymbol{\square}$, repeat $1 ; \boldsymbol{\bullet}$, repeat 2 ; and $\mathbf{\Delta}$, repeat 3 ). Percentage of spores released on the $\mathrm{Y}$ axis against time was the percentage of spores trapped during the previous hour, beginning at $2200 \mathrm{~h}$. RH shown was the record for the first replication; RH for the other two replications had similar patterns. repeated variable. The data also were subjected to analysis of variance combined with the Student-Newman-Keuls test. All analyses were performed using SAS version 6.12 (SAS Institute, Cary, NC).

\section{RESULTS}

Light initiations and spore release. There were significant effects of light-initiation treatments and time on spore release (Table 1). For all three light-initiation treatments and three repetitions of each treatment, some spore release occurred throughout the day, but it increased after light initiation and reached a maximum after 1 or $2 \mathrm{~h}$ of light (Fig. 3). For light initiations beginning at 0400 and $0600 \mathrm{~h}$ (circadian time), the percentage of spores trapped de-
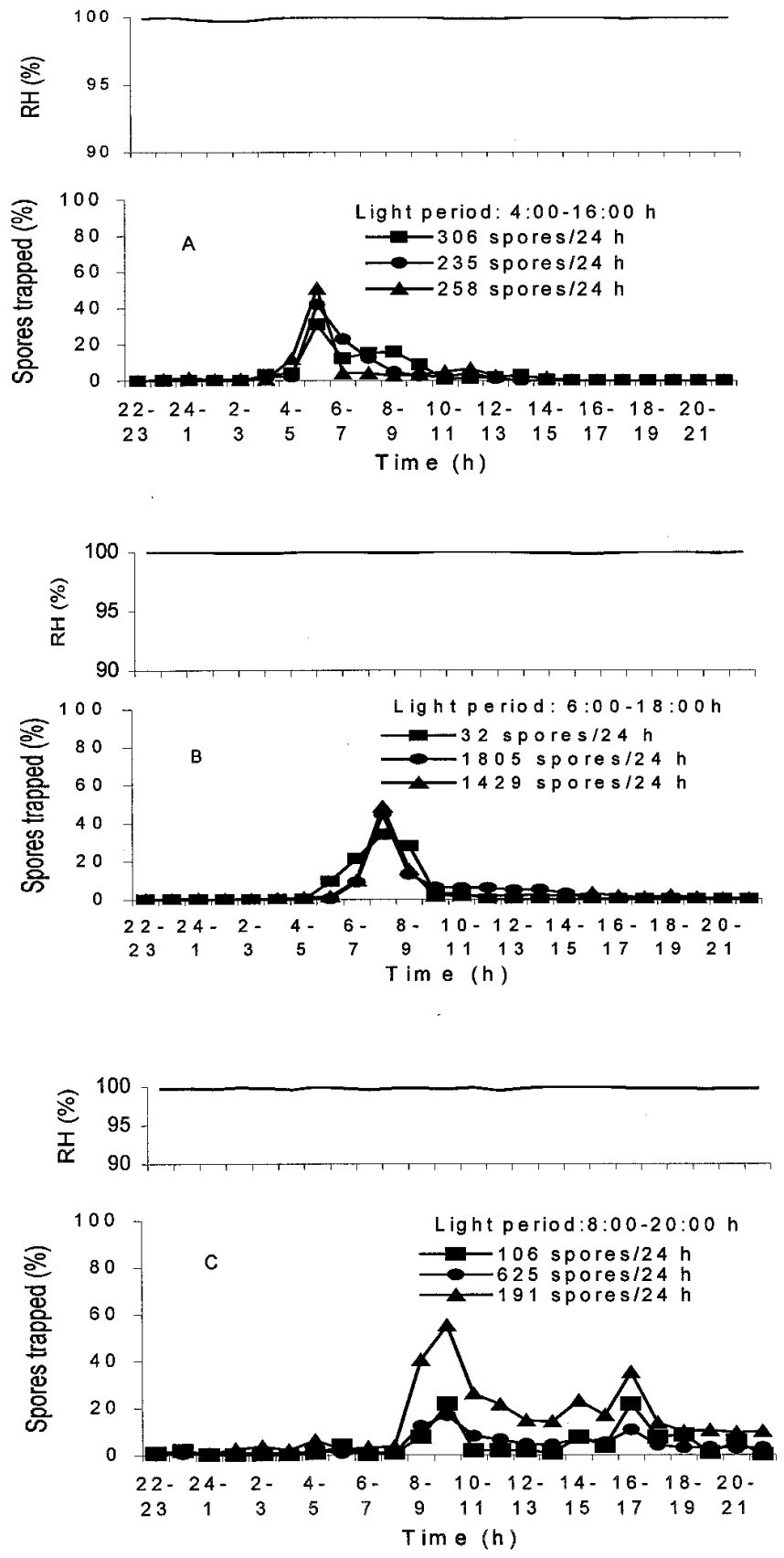

Fig. 3. Percentage of spores trapped in three light initiation experiments (A, B, and C) during 24-h periods, beginning at $2200 \mathrm{~h}$, circadian time, each day. Spores were trapped during three 24-h periods for each initiation $(\mathbf{\square}, \mathrm{re}-$ peat 1; $\bullet$, repeat 2; and $\mathbf{\Lambda}$, repeat 3). Percentage of spores released on the $\mathrm{Y}$ axis against time was the percentage of spores trapped during the previous hour. Relative humidity (RH) shown for each light treatment was the record for the first replication; RH for the other two replications had similar patterns. 
creased sharply after the spore-release peak, and then gradually until only a few spores were trapped. A second increase of spore release at $\approx 1600$ to $1700 \mathrm{~h}$ was detected for each replication of light period 0800 to $2000 \mathrm{~h}$ (Fig. 3C; Table 2) but not for the other two light-initiation treatments (Fig. 3A and B; Table 2). Results were consistent between experiments (Table 1).

Reduction in RH and spore release. Reduction in $\mathrm{RH}$ before or after light initiation had a significant effect on spore release (Table 1). When RH was reduced at $0600 \mathrm{~h}$ ( $2 \mathrm{~h}$ before light initiation) spores trapped increased immediately after the reduction in $\mathrm{RH}$, reached a peak after an hour and then decreased (Fig. 2A). When the onset of light occurred at $0800 \mathrm{~h}$, spores were released again in a similar pattern to that observed in the light-initiation experiments. When RH decreased at $1000 \mathrm{~h}$, after the light had been on since $0800 \mathrm{~h}$, an initial spore-release peak occurred after $1 \mathrm{~h}$ of light, followed by a further increase after a drop in $\mathrm{RH}$, reaching a maximum $1 \mathrm{~h}$ later (Fig. 2B; Table 2). There was a small second spore release peak for both treatments (Fig. 2A and B).

\section{DISCUSSION}

In this study, we showed that both light initiation and reduction in RH could trigger spore release of $B$. lactucae. Peak spore release by $B$. lactucae occurred 1 to $2 \mathrm{~h}$ after light initiation. Effects of light and RH on spore release of other members of the Peronosporales had been demonstrated earlier $(16,17)$ but not for $B$. lactucae. Scherm and van Bruggen (24) assumed that light might trigger spore release of $B$. lactucae, and this hypothesis was confirmed in this study. Thus, lettuce downy mildew, like most other downy mildews (22), has a diurnal pattern of spore liberation. Similarly, spores of $P$. destructor also are released after sunrise before a reduction in $\mathrm{RH}$ (7), suggesting that light was a separate factor triggering spore release of this fungus. This is consistent with the fact that sporulation of B. lactucae requires darkness (27).

Light may increase the rate of dehydration of sporangia (12) and it is difficult to differentiate this effect from that caused by a reduction in $\mathrm{RH}$ even under precisely controlled conditions. When a $\mathrm{RH}$ probe without radiation shelter was used, the RH reading decreased greatly in a $100 \% \mathrm{RH}$ environment because of the increased evaporation from the sensor's surface $(\mathrm{H}$. Su, A. H. C. van Bruggen, and K. V. Subbarao, unpublished data). A similar process also may occur on the surfaces of sporangia or sporangiophores (12).

The minimum RH obtained was $94 \%$, although $81 \%$ was expected, using a super-saturated ammonium sulfate solution. This may be due to the large volume of the trap chamber formed by two crisper boxes attached to the RH chamber, because a constant $81 \% \mathrm{RH}$ was reached in other experiments with a single crisper box $(\mathrm{H} . \mathrm{Su}$, A. H. C. van Bruggen, and K. V. Subbarao, unpublished data). Nevertheless, a $6 \%$ decrease in absolute RH triggered spore liberation, suggesting that sporangia of $B$. lactucae are sensitive to small changes in humidity in the environment, as are sporangia of $P$. parasitica (20).

TABLE 2. Results of the Student-Newman-Keuls (SNK) test of the percentage of spores released per hour during 24-h periods in three light-initiation treatments at $100 \%$ relative humidity $(\mathrm{RH})$ and two RH-reduction treatments

\begin{tabular}{llccrl}
\hline & & \multicolumn{4}{c}{ SNK group (time, $\mathrm{h})^{\mathrm{y}}$} \\
\cline { 3 - 6 } Experiment & Treatment (h) & 1 & 2 & 3 & 4 \\
\hline Light timing & $0400-1600$ & $0600 \mathrm{a}$ & $0700 \mathrm{~b}$ & $X \mathrm{bc}$ & $\ldots$ \\
& $0600-1800$ & $0800 \mathrm{a}$ & $0900 \mathrm{~b}$ & $0700 \mathrm{c}$ & $X \mathrm{~d}$ \\
& $0800-2000$ & $1000 \mathrm{a}$ & $1700 \mathrm{ab}$ & $X \mathrm{~b}$ & $\ldots$ \\
$\mathrm{RH}^{\mathrm{z}}$ & RH 1 & $0900 \mathrm{a}$ & $1000 \mathrm{a}$ & $0700 \mathrm{~b}$ & $X \mathrm{bc}$ \\
& RH 2 & $1100 \mathrm{a}$ & $1000 \mathrm{~b}$ & $X \mathrm{c}$ & $\ldots$ \\
\hline
\end{tabular}

${ }^{y}$ Means followed by the same letter in each row are not significantly different at $P=0.05 ; X=$ remaining hours in a $24-\mathrm{h}$ period; $\ldots=$ data not collected.

${ }^{\mathrm{z}} \mathrm{RH}$-reduction treatments with light initiation at $0800 \mathrm{~h}$, circadian time: $\mathrm{RH} 1=$ 100 to $94 \%$ RH $2 \mathrm{~h}$ before $0800 \mathrm{~h}$ and $\mathrm{RH} 2=100$ to $94 \% \mathrm{RH} 2 \mathrm{~h}$ after $0800 \mathrm{~h}$.
Not all spores present were discharged by light initiation or the reduction in $\mathrm{RH}$ in this study. Spores were released again when light initiation followed a reduction in RH. Similarly, reduction in $\mathrm{RH} 2 \mathrm{~h}$ after light initiation continued to trigger spore release of B. lactucae. The reason may be that the reduction in RH was not great enough to liberate all spores in the first case and the effect of light on evaporation of the surfaces of spores or sporangiophores was not strong enough in the second case. This phenomenon also was described by Leach et al. (17) for spore release of $P$. destructor. Spores of $P$. destructor were discharged continuously by infrared (IR) treatment after a decrease in RH from 100 to $36 \%$, suggesting that the degree of reduction in $\mathrm{RH}$ was not a main reason for the above phenomenon. Additional spore release of $P$. destructor was also detected when the RH was reduced from 100 to $45 \%$ after IR was applied. Leach (16) considered spore release of $P$. destructor an active discharge driven by electrostatic charges. Possibly the electric charges resulting from one factor were not strong enough to discharge all the spores. However, other mechanisms may contribute to the release of all the spores. The process of maturation of spores, and the effects of light and dehydration on spore maturation, should be investigated further to better understand this phenomenon.

A second peak of spore release was detected when the light period was 0800 to $2000 \mathrm{~h}$, even when no reduction in $\mathrm{RH}$ was imposed. In $D$. turcica, more peaks during a period of decreasing RH or at constant RH were detected (12). In this study, the secondary spore release in $B$. lactucae may be due to maturation of spores produced before light started. According to Verhoeff (27), 6 to $7 \mathrm{~h}$ of darkness are needed to produce sporangiophores. The spores trapped could mostly be the spores produced on the sporangiophores formed during the dark period from 1600 to $0400 \mathrm{~h}$ during the night before plants were moved into the trap chamber. When plants were moved into the trap chamber at $2200 \mathrm{~h}$ and exposed to a light period from 0800 to $2000 \mathrm{~h}, 8 \mathrm{~h}$ more darkness was applied than during incubation, and there was enough time for spore production on the sporangiophores formed during the same night. This may explain why a second peak in spore release was observed only for the light period of 0800 to $2000 \mathrm{~h}$. When treatments of RH reduction were introduced for the same light period, most of the spores were released because of the enhanced treatments of both light and RH; therefore, the second peak became much weaker.

The spore trap used in this experiment is easy to build and suitable for experiments under controlled environmental conditions. It can also be used for studying spore release of other fungi. The trap and plant samples should be in a sealed container, as in prototypes built by Leach (13) and Gottwald (5), to maintain a precisely controlled environment; therefore, the size of the container needs to be adjusted to the size of the plants unless detached samples will be used. However, detached samples may not be ideal to study spore release of obligate fungi because the physiological condition of the host might change in detached samples, thus affecting the spore release of the fungus.

The results of this study have important implications for the implementation of a forecasting system for lettuce downy mildew. Under optimal temperature, B. lactucae spores can establish infection with less than $4 \mathrm{~h}$ of leaf wetness. Based on the observations that spore release and infection could occur during the same morning and the assumption that spores would be released at $0600 \mathrm{~h}$, a forecasting system was developed in which a fungicide spray was recommended if leaf wetness lasted until at least 10:00 a.m. (25). Results from this study confirm that spore release is triggered by light, especially under conditions of leaf wetness on at least part of the crop when RH may still be high.

\section{ACKNOWLEDGMENTS}

This research was funded by USDA NRI grant 96-35313-3752 to A. H. C. van Bruggen, K. V. Subbarao, and R. W. Michelmore. 


\section{LITERATURE CITED}

1. Bell-Pedersen, D., Garceau N., and Loros, J. J. 1996. Circadian rhythms in fungi. J. Genet. 75:387-401.

2. Davis, D. R., and Sechler D. 1966. A simple, inexpensive, continuous sampling spore trap. Plant Dis. Rep. 50:906-907.

3. Decker, H. M., and Wilson, M. E.. 1954. A slit sampler for collecting airborne microorganisms. Appl. Microbiol. 2:267-269.

4. Fletcher, J. T. 1976. Bremia lactucae, oospores, sporangial dissemination and control. Ann. Appl. Biol. 84:294-298.

5. Gottwald, T. R., Trocine T. M., and Timmer, L. W. 1997. A computercontrolled environment chamber for the study of aerial fungal spore release. Phytopathology 87:1078-1084.

6. Gregory, P. H. 1954. The construction and use of a portable volumetric spore trap. Trans. Br. Mycol. Soc. 37:391-404.

7. Hildebrand, P. D., and Sutton, J. C. 1982. Weather variables in relation to an epidemic of onion downy mildew. Phytopathology 72:219-224.

8. Hirst, J. M. 1952. An automatic volumetric spore trap. Ann. Appl. Biol. 39: 257-265.

9. Hopkins, J. C. 1959. A spore trap of the 'Vaseline' slide type. Can J. Bot. 37:1277-1278.

10. Kurkela, T. 1994. A sampler making discrete spore prints, useful for spore release studies. Karstenia 34:65-78.

11. Leach, C. M. 1975. An electrostatic theory to explain violent spore liberation by Drechslera turcica and other fungi. Mycologia 68:63-86.

12. Leach, C. M. 1975. Influence of relative humidity and red-infrared radiation on violent spore release by Drechslera turcica and other fungi. Phytopathology 65:1303-1312.

13. Leach, C. M. 1980. An apparatus for precise control of humidity, temperature, air flow, and light in spore discharge studies. Phytopathology 70:189-191.

14. Leach, C. M. 1980. Evidence for an electrostatic mechanism in spore discharge by Drechslera turcica. Phytopathology 70:206-213.
15. Leach, C. M. 1980. Influence of humidity and red-infrared radiation on spore discharge by Drechslera turcica-Additional evidence. Phytopathology 70:192-196.

16. Leach, C. M. 1982. Active sporangium discharge by Peronospora destructor. Phytopathology 72:881-885.

17. Leach, C. M., Hildebrand, P. D., and Sutton, J. C. 1982. Sporangium discharge by Peronospora destructor: Influence of humidity, red-infrared radiation, and vibration. Phytopathology 72:1052-1056.

18. Meredith, D. S. 1973. Significance of spore release and dispersal mechanisms in plant disease epidemiology. Annu. Rev. Phytopathol. 11:313-342.

19. Panzer, J. D., Tullis, E. C., and Van Arsdel, E. P. 1957. A simple 24-hour slide spore collector. Phytopathology 47:512-514.

20. Pinckard, J. A. 1942. The mechanism of spore dispersal in Peronospora tabacina and certain other downy mildew fungi. Phytopathology 32:505511.

21. Powlesland, R. 1954. On the biology of Bremia lactucae. Trans. Br. Mycol. Soc. 37:362-371.

22. Royle, D. J., and Kremheller, H. T H. 1981. Downy mildew of the hop. Pages 395-419 in: The Downy Mildews. D. M. Spencer, ed. Academic Press, London.

23. Schenck, N. C. 1964. A portable, inexpensive, and continuously sampling spore trap. Phytopathology 54:613-614.

24. Scherm, H., and van Bruggen, A. H. C. 1995. Concurrent spore release and infection of lettuce by Bremia lactucae during morning with prolonged leaf wetness. Phytopathology 85:552-555.

25. Scherm, H., Koike, S. T., Laemmlen, F. F., and van Bruggen, A. H. C. 1995. Field evaluation of fungicide spray advisories against lettuce downy mildew (Bremia lactucae) based on measured or forecast morning leaf wetness. Plant Dis. 79:511-516.

26. Thomas, B., and Vince-Prue, D. 1997. Photoperiodism in Plants. Academic Press, London.

27. Verhoeff, K. 1960. On the parasitism of Bremia lactucae Regel on lettuce. Overdruk Uit Tijdschr. Plantenziekten 66: 133-203. 